\section{Thesis abstracts}

\section{The antimutagenic and anticarcinogenic effect of propolis in Wistar rats}

\section{Ana Paula Bazo*}

The antimutagenic and anticarcinogenic effects of propolis, a honeybee product, were evaluated in male Wistar rats, using the comet assay and the aberrant crypt foci (ACF) assay. For both tests, animals were treated with the colon carcinogen 1,2 dimethylhydrazine (DMH) for two weeks (two s.c. injections/week) to induce DNA damage and ACF. The animals were divided into groups that received 3 different propolis concentrations (10,30 and 90 $\mathrm{mg} / \mathrm{kg}$ b.w., by gavage), either pre- and simultaneously with DMH (ACF and comet assay), or post- DMH treatment (ACF assay). Blood samples were collected from the periorbital vein plexus $4 \mathrm{~h}$ after the last DMH treatment for the comet assay. For the ACF assay, the animals were sacrificed two weeks after the last DMH injection. The results showed that propolis had no clear effect on DNA damage induced by DMH in blood cells when evaluated by the comet assay. However, when administered after DMH, propolis caused a significant reduction in the total number of aberrant crypts in the distal colon. These results suggest that propolis does not clearly protect blood cells against DMH genotoxicity, but it has a protective effect on the development of colon carcinogenesis, reducing preneoplastic lesions.

*2000. Pós-Graduação em Ciências Biológicas. Área de Concentração: Genética. Instituto de Biociências, UNESP, Botucatu, SP, Brasil. Master's thesis. Orienting Professor: Dra. Daisy Maria Fávero Salvadori.

\section{Mitochondrial DNA polymorphism and popula- tion structure in Astyanax (Pisces, Characidae)}

\section{Cinthia Bachir Moysés*}

The genus Astyanax (Pisces, Characiformes) is widely distributed in the Neotropical region. However, the evolutionary relationship among species of this group of freshwater fish is still poorly understood. In the present study, restriction fragment length polymorphism analysis of mitochondrial DNA (mtDNA) was used to assess intraand interspecific genetic variability and population structure of four species belonging to the genus Astyanax: $A$. bimaculatus, A. fasciatus, A. schubarti and A. scabripinnis. Populations from the Upper Paraná and São Francisco basins were sampled.

MtDNA exhibited considerable polymorphism within and among species, as well as within and among populations. Two types of mtDNA heteroplasmy were detected in some specimens of $A$. bimaculatus: one involving
mtDNA length and the other involving a single restriction site. All the populations sampled, with the exception of $A$. scabripinnis populations, have shown relatively high values of haplotype diversity.

Species generally have geographically localized haplotypes, which suggests that populations have been isolated for a long time. However, A. bimaculatus and $A$. fasciatus populations from Pirassununga and Penápolis share a number of haplotypes. Since these localities are geographically distant, this pattern could be related to the occurrence of gene flow through neighboring populations. Also some populations of $A$. scabripinnis have haplotypes in common. Populations from the Upper Paraná and São Francisco basins did not share any haplotypes.

There is a remarkable haplotype divergence between populations of $A$. bimaculatus and A. fasciatus from the Upper Paraná and São Francisco basins, which was corroborated not only by statistical tests but also by maximum parsimony and distance trees.

It is suggested that $A$. fasciatus and A. scabripinnis may be closely related species. On the other hand, $A$. bimaculatus seems to be a more differentiated species in relation to A. fasciatus, A. schubarti and A. scabripinnis. The lineage leading to $A$. bimaculatus is likely to have diverged prior to the other three species or, alternatively, the rate of mtDNA evolution might be higher in this lineage.

*1999. Departamento de Biologia, Instituto de Biociências, Universidade de São Paulo, São Paulo, SP, Brasil. Master's thesis. Orienting Professor: Dra. Lurdes Foresti de Almeida-Toledo.

\section{Cytogenetic and molecular characterization of $4 p$ deletions that cause Wolf-Hirschhorn syn- drome}

\section{Érica Paula Portioli Silva*}

Wolf-Hirschhorn syndrome (WHS) is a rare anomaly, with an incidence of 1/50,000 live births, characterized by mental and growth retardation and characteristic facial signs known as Greek-helmet, including prominent glabella, hypertelorism and beak-like nose. Other important characteristics are the defects of midline fusion, which include cleft lip and/or palate, bifid uvula, coloboma and hypospadias. This syndrome is caused by a partial deletion of the chromosome 4 short arm. The $165-\mathrm{kb}$ genomic segment defined as the critical region in segment $4 \mathrm{p} 16.3$ is located between loci D4S98 and D4S166. Two genes have been identified in thus region, $\mathrm{WHSC}_{1}$ and $\mathrm{WHSC}_{2}$.

Clinical, cytogenetic (G banding and FISH) and molecular (PCR) studies were performed in seven WHS patients and their parents. In four of seven patients the deletion was evident by $\mathrm{G}$ banding chromosome analysis and in two of them only after FISH analysis; one patient with apparently normal chromosomes had the deletion 
detected after microsatellite analysis of loci located in $4 \mathrm{p} 16.3$. Five of the patients showed de novo deletions, one inherited the derivative chromosome 4 from the father who had a balanced translocation between chromosomes 4 and 8 $[46, X Y, t(4 ; 8)(p 16.3 ; \mathrm{q} 24)]$. The mother of one patient had a chromosomal mosaicism [46,XX/46, XX, del(4) (p16.3pter)] detected by FISH analysis. Paternal origin of the deleted chromosome 4 was evident in six patients and the maternal origin was confirmed for patient 7 .

All our patients showed the main WHS characteristics regardless of deletion length or parental origin. Patient 4 with the smallest deletion presented better neuropsychomotor development and less severe mental retardation. Prognosis seems to be better when the deletion involves mainly WHSCR.

The recurrence risk for de novo deletions is lower than $2 \%$, but the father with balanced translocation has a high risk of monosomic or trisomic $4 p$ offsprings $(\sim 50 \%)$ and unidentified abortions, stillbirths and neonatal deaths $(\sim 30 \%)$. The mother with the chromosome mosaicism, at least in lymphocytes, has an unknown recurrence risk. Prenatal diagnosis is highly recommended for these two parents

Cytogenetic studies in WHS patients and their parents are very important for diagnosis, prognosis and genetic counseling, and to provide important information about prenatal diagnosis to those families.

*2000. Dpto. Biologia, IBUSP. Master's thesis. Orienting Professor: Dra. Celia P. Koiffmann

\section{Evolutionary-genetical study of modern and ar- chaeological Maize (Zea mays mays L.) and common bean (Phaseolus vulgaris L.) samples}

\section{Fábio de Oliveira Freitas*}

Seven archaeological maize samples (Zea mays, Lineu), $620 \pm 60$ to $990 \pm 60$ years old and one common bean sample (Phaseolus vulgaris, Lineu), $301 \pm 39$ years old (based on $\mathrm{C}^{14}$ dating), were studied using biomolecular techniques to understand their historical origin. They were found in indigenous subterranean silos at archaeological sites at Januária (Peruaçu Valley), Minas Gerais state, Brazil.

A segment of the nuclear gene encoding alcohol dehydrogenase 2 (Adh2) was amplified and sequenced from extracts of the maize specimens, while two segments of the nuclear gene encoding the Phaseolin protein were used from the common bean sample.

Three Adh 2 main allele groups, which were previously known in the maize center of origin in Central America, were observed in the maize samples. These groups have also been found in South America, but presenting a characteristic geographical distribution. One of the alleles, considered the most primitive, occurs in the Andean highlands. The other two are mainly present in lowlands, but one of them restricted to the São Francisco and Paraná-Paraguai river basin, along the Atlantic coast.

These data suggest that, historically, different maize varieties were introduced into South America, perhaps in two different periods, and spread to distinct regions by migrating or trading human populations. The first introduction is estimated to have occurred about 5,000 years ago, and the second and possibly a third, about 3,000 years later. These introductions must be responsible for the high-/lowland distribution pattern, which has been maintained up to today. The European colonisation of the South America in the $15-16^{\text {th }}$ century kept this pattern. Portugal conquered the lowlands and Spain the highlands and they maintained a cultural and trade barrier for a long time. However, in the Southern part of South America there must have been some exchange, since alleles from lowlands were found in archaeological sites in Chilean highlands, and conversely, highland alleles were present in one modern indigenous sample from Paraguay. It should be mentioned that archaeological and modern alleles found in Peru are remarkably different from those in Brazil. This would mean that Brazilian indigenous populations must have been more influenced by Central America culture than by that of the Andean highlands.

The Januária common bean sample, which was identified as Phaseolus vulgaris, presents the basic genetic type of $\alpha$ Phaseolin. The alleles from modern samples from Mexico to Argentina indicate the presence of a geographical distribution pattern. Alleles sampled from Mexico to the Northern region of South America (Colombia, Ecuador and Northern Peru) belong to the same group, called the Northern alleles group, while those from Southern Peru to Argentina belong to another group, called the Southern alleles group.

Apparently the Northern group of alleles are older, pointing to the corresponding region as the centre of the origin for Phaseolus vulgaris. The southern group of alleles must have been derived from those from the North. This confronts some theories that suggest more than one and independent centre of origin for the common bean.

The Januária sample had six different alleles, two identical to the Northern group. Of the remaining four, two were very close to the Northern group, while the other two may be considered intermediary. No allele similar to the Southern group was found. The conclusion is that the common bean sample from Januária is genetically closer to the Northern populations but has vestiges of contacts with populations from the Central and Southern Andean regions.

Together, the maize and common beans populations from Januária seem to have had a greater relationship or influence from materials originating in Central America and very little with those from the Central Andes, such as Peru. 
Furthermore, higher genetic diversity was observed within common bean than maize genes.

Finally, this research showed that plant archaeological samples from the Tropics may contain well preserved genetic material suitable for evolutionary studies and may provide data to understand the life history of mankind in the Americas.

*2001. Pós-Graduação em Genética e Melhoramento de Plantas. Departamento de Genética. Escola Superior de Agricultura Luiz de Queiroz, Universidade de São Paulo, SP, Brasil. Doctor thesis. Orienting Professor: Dr. Gerhard Bandel.

\section{Description and analysis of plant material from archeological sites in Januária, Minas Gerais}

\section{Fábio de Oliveira Freitas*}

Archaeological excavations performed since the late 70's in the Peruaçu Valley, Januária, Minas Gerais state, Brazil, by Dr André Prous and his associates from the Federal University of Minas Gerais, have recovered plant species that were used by prehistorical people in this region.

These vestiges contain cultivated and collected materials packaged in braided palm leaf baskets that were buried, called "silo". Maize (Zea mays mays) is the most common cultivated species in the silos, and fragments of guariroba palm fruit (Syagrus oleracea) is the most abundant collected species.

Part of this material and two pieces of cassava (Manihot esculenta) were analysed. The age of these materials was estimated using radiocarbon dating by benzene technique and liquid scintillation counting, done in CENA/ USP, using guariroba palm fruit and two charcoal samples.

The estimated age ranges from 1010 years for the oldest sample, and 570 years for the most recent one. The cassava fragment is 860 years old.

The maize cob was analysed morphologically using length, basal and apical diameters, largest diameter, number of rows, number of grains/ row, and number of grains/ row/length.

The starch present in the reserve organs of the maize and cassava were analysed morphologically for shape and size, using a sample of 300 starch grains for each grain under a scanning eletronic microscope.

For comparison, 21 accessions of indian maize races and ethnovarieties from the CNPMS/ EMBRAPA Germplasm Bank, Sete Lagoas, MG, were analysed statistically.

Through the analysis it was concluded that:

The starch in the maize and cassava reserve organs was in an excellent state of conservation.

The starch grain morphology permitted the separation of maize races and varieties.

During the dated period (1010 to $570 \mathrm{BP}$ ) diversity in the varieties of maize being cultivated was detected and that, at the same time, the prehistorical people were cultivating more than one variety.

Three patterns of distribution of starch grain size were observed, one with a peak of small grains, another following a normal curve and other with medium size grains.

These distribution patterns can be used to characterize some of the studied races of maize.

The pattern of variation in the size of the maize starch grains suggests that part of the gene pool of the traditional Brazilian races Cateto, Caigang, Guarani Complex, Cristal, Entrelaçado, Moroti and Pontinha São Simão, were present in a larger or smaller proportion in the material cultivated by the prehistoric human populations which lived at least 1.000 years ago in the northern region of Minas Gerais.

The starch morphology confirmed that the tuber fragment was cassava.

*1997. Pós-Graduação em Genética e Melhoramento de Plantas. Departamento de Genética, Escola Superior de Agricultura Luiz de Queiroz, Universidade de São Paulo, SP, Brasil. Master. Orienting Professor: Dr. Paulo Sodero Martins.

\section{Microsatellite in Nectomys squamipes (Rodentia, Sogmodontinae): Locus identifica- tion and application in a population study}

\section{Francisca Cunha Almeida*}

The study of population parameters and processes operating on natural populations allows a better understanding of the evolutionary history and future of species. Indirect estimates of demographic parameters may be obtained by analyzing genetic variation with molecular techniques. This dissertation describes the identification of several microsatellite loci and a population study of Nectomys squamipes, a semi-aquatic rodent species with a wide geographic distribution in South America. Thirty three loci were identified, the majority of which showed a (GT) notif. Primer sequences for PCR amplification were obtained for 15 loci. Eight of these loci were characterized in respect to their variability in a sample of individuals from different localities. Three loci were found to be monomorphic while five others were highly variable, with a high number of alleles (12 to 25) and heterozygosity values. Linkage disequilibrium was not detected between any pair of loci, thus confirming their suitability for population analysis. Polymorphic loci were subsequently used to investigate the genetic variability and structure of six mainland and two island populations of $N$. squamipes. High levels of variability were found within each mainland population while the island populations showed lower levels. Deviations from the expected Hardy-Weinberg equilibrium estimates were not detected. Island populations were found to be the most differentiated among all populations for allele frequencies and size. A significant geographic structure was found in the mainland populations $\left(\mathrm{F}_{\mathrm{ST}}=0.090, \mathrm{R}_{\mathrm{ST}}=0.065\right)$ 
although the degree of differentiation was relatively low in relation to distances of surveyed localities (24 to $740 \mathrm{~km}$ ). Genetic and geographic distances did not correlate positively, showing absence of isolation by distance pattern among the mainland populations, which is in line with previous data from RAPD markers in five populations herein analyzed. This finding indicates a lack of equilibrium between migration and drift, resulting in an error in estimating gene flow. Heterozygosity values allowed for the estimation of high, effective population sizes preventing drift effects in local demes, which might explain the low levels of differentiation and lack of equilibrium in mainland populations. When considering ecological data from field studies, these results indicated that a panmictic population might occupy a very extensive area. Lower estimates of effective size in island populations were probably due to bottleneck effects related to changes in sea levels.

*2000. Dissertação submetida ao Programa de Pós-graduação em Genética da Universidade Federal do Rio de Janeiro -UFRJ, como parte dos requisitos necessários para a obtenção de grau de Mestre. Orienting Professor: Dr. Rui Cerqueira.

\section{Statistical analysis and application of aug- mented block design in plant breeding}

\section{João Batista Duarte*}

This research investigated experimental and statistical problems related to the use of the augmented block design in plant breeding programs. A characteristic of these designs is that treatments are of two categories, namely: common checks (generally commercial varieties replicated over blocks) and the additional or new treatments (usually not replicated) that are genotypes under evaluation for selection purposes. The relationship of this design with the commonly used block designs, the requirements for its applications and analysis and some information about other topics (mixed models, components of variance and spatial analysis) were reviewed in Chapter 1. Only trials with a complete layout of the plot spatial positions in the field were taken for analysis and discussion. The grain yield trait $(\mathrm{kg} / \mathrm{ha})$ of a group of 41 trials, which were set up at the Department of Genetics (ESALQ, USP) for evaluating soybean inbred lines, was used for the analyses and discussions. It is known that these trials are usually conducted at preliminary stages, when genotypes can be statistically assumed as random effects, or at intermediate and final stages when they are preferentially considered fixed effects. The first interesting point to investigate was the influence of these assumptions on the genotype mean estimates and ranking for selection purposes (Chapter 2). The assumptions opened the possibility of considering either fixed or mixed models for analysis (intrablock analysis, or others with use of interblock or intergenotypic information). Chapter 3 shows the corresponding analytical procedures and their consequences on the ranking and selection of genotypes. Under mixed models a fundamental step is the estimation of variance components, for which several procedures are available. It is known that these procedures may lead to different estimates of the same parameter, especially when experiments are unbalanced. Due to the lack of specific information about this point, and since these designs are naturally unbalanced, computer simulations were made to assess the properties of the different available estimators, specifically: $A N O V A, M I V Q U E(0), M L$ and $R E M L$ (Chapter 4). An additional characteristic of these designs, at initial stages of breeding programs, is the use of small-sized plots, necessary to accommodate the small amount of seeds available. This fact, in addition to the common practice of systematic arrangement of check plots in the field and/or the arrangement of genetically related treatments in sets, motivated the application of spatial statistics procedures (Chapter 5). The following main results and conclusions can be pointed out: $i$ ) the intrablock analysis (fixed model) can provide inadequate ranking of the genotypic means if genotypes have random effects and especially if they derive from different populations (Chapter 2); ii) the classification of the new genetic treatments in relation to check varieties may change considerably, depending on the model adopted, especially when the intrablock and the analyses with the use of intergenotypic information are compared (Chapter 3); iii) the MIVQUE(0) method, in general, supply more efficient estimates of variance components, particularly if genotypes are derived from population(s) with low genotypic variance(s) and experiments are of small size (Chapter 4); and, iv) if the experimental observations are spatially correlated the discrimination among genotypes and the ranking of genetic treatments can be substantially improved through spatial statistical analysis (Chapter 5).

*2000. Departamento de Genética. Escola Superior de Agricultura "Luiz de Queiroz", Universidade de São Paulo (ESALQ-USP), Piracicaba, SP, Brasil, Doctoral thesis. Orienting Professor: Dr. Roland Vencovsky.

\section{Mutagenic evaluation of cannabidiol, a mari- huana compound, by micronucleus and comet assay cytogenetic tests}

\section{Leni Gomes*}

The plant Cannabis sativa L., also known as marihuana or maconha has been cultivated by man for many years. Despite its reputation as an abuse drug the plant has therapeutic qualities and has been indicated especially as an analgesic or antiemetic substance. This plant contains a considerable amount of the nonpsychoactive compound, cannabidiol (CBD). It has been indicated as an anticonvulsant in view of the depressive effect it produces on neuromuscular transmission and response, both in laboratory animals and in man. The efficacy of this substance has 
been assessed in the control and treatment of epileptic convulsions and dystonic movement disorders. The mutagenic potential of a drug or substance evaluated by some cytogenetic tests such as the micronucleus (MN) and the comet (SCGE) assays. Micronuclei are represented by chromosomal material in the cell cytoplasm, derived from acentric DNA fragments or complete chromosomes which failed to attach to the mitotic spindle. On the other hand, the comet assay permits the identification of DNA fragments in isolated cells that run away from the main nucleus when subjected to electrophoresis, resulting in a figure that resembles a comet. Preliminary studies have shown that the use of CBD may increase the frequency of chromosomal aberrations in human lymphocytes treated in vitro, as well as numerical changes in polychromatic mice erythrocytes, in vivo. In the present investigation, the $\mathrm{MN}$ frequency and comets was evaluated in human lymphocytes exposed to CBD dissolved in ethanol $(0.01 \mathrm{ml} / \mathrm{ml}$ medium $)$ at concentrations of 0,$001 ; 0,01 ; 0,1 ; 1,0$ and $10,0 \mu \mathrm{g} \mathrm{CBD} / \mathrm{mL}$ medium. The lymphocyte cultures were obtained from peripheral-blood samples taken from six donors, 3 male and 3 female, mean age $27.7 \pm 2.1$ years. After $48 \mathrm{~h}$ in culture the CBD dissolved in ethanol, or ethanol alone, did not increase the frequency of $\mathrm{MN}$ in binucleated lymphocytes $(p>0.25)$. However, when compared to the control, the culture treated with CBD dissolved in ethanol showed a statistically significant difference in the frequency of comets. The main difference was detected in the cultures with $0.01 \mu \mathrm{g} \mathrm{CBD} / \mathrm{mL}$ medium. Similar results were also observed in the cultures with ethanol. All the cells in the comet assay were analyzed by the morphological and image systems and the comparison between the two methods showed a statistically significant correlation $(\mathrm{p}<0.01)$. These data suggest that the comet assay can be performed even if an image analyzer is unavailable. Although the MN frequency remained unchanged, the frequency of comets was increased in a statistically significant way by the CBD dissolved in ethanol - which suggests mutagenic effect of $\mathrm{CBD}$ in vitro. Taking into consideration the large consumption of marihuana and the therapeutic potential of CBD, further mutagenic tests should be undertaken, especially in the in vivo systems, before this substance can be prescribed.

*2000. FMUSP, São Paulo. Dissertação de Mestrado. Orienting Professor: Dra. Gilka Jorge F. Gattás.

\section{Small mammals, with special emphasis in ro- dents (Rodentia) in Ilha Grande, RJ. A genetic and biogeographical approach to Atlantic Forest remnants}

\section{Luciana Guedes Pereira*}

The present study compared the small mammal fauna in an area from $22^{\circ} 51^{\prime} \mathrm{S}, 44^{\circ} 00^{\prime} \mathrm{W}$ to $23^{\circ} 29^{\prime} \mathrm{S}, 45^{\circ} 10^{\prime} \mathrm{W}$, including some islands and the adjacent continental area of
Rio de Janeiro State, consisting of 11 localities. Data allowed a cytogenetic and molecular sequence analysis (DNAmt) characterization of isolated populations relating them to continental populations with continuous distribution.

Isolated populations on islands tend to show distinctive evolutionary patterns when compared to those that are continental and are spread over wide areas. Ilha Grande (Angra dos Reis municipality) was separated from the continent about 7 thousand years ago and is part of the Atlantic Forest of the Brazilian coast, considered an example of vegetational fragmentation. In addition to the isolation effect, geographic variation studies at different knowledge levels is important to understand evolution in rodents of the Sigmodontinae subfamily, as we know that they have one of the most accelerated molecular evolutionary rates and one of the highest chromosomal rearrangement rates.

The material used in this investigation was collected from natural populations (field effort and information obtained from collections and literature). Twenty-one (64\%, including those species that occur both on the continent and in the island) of the 33 species of five orders of small mammals occur on Ilha Grande, showing that the isolation period has not reduced the biodiversity drastically.

Some Sigmodontinae rodent species (Oryzomys russatus, Nectomys squamipes, Oxymycterus dasytrichus and Rhipidomys sp.), and Trinomys dimidiatus (Echimyidae), showed that samples from Ilha Grande maintain more variation in diploid (2n) and fundamental number (FN, excluding sexual pair), except for $T$. dimidiatus that showed an inverse result. $O$. russatus showed a higher $2 \mathrm{n}$ in some specimens and NF in the whole sample, differing from that described in the literature, with the addition of one pair of autosomes. Only one specimen from $N$. squamipes collected on Ilha Grande also differed in the 2n. FN differed from 56 to 60 in samples from 3 localities. O. dasytrichus and Rhipidomys sp. presented a different FN only in the sample collected on Ilha Grande probably because of the isolation. Thus it was concluded that these four species showed more difference (two species in $2 \mathrm{n}$ and all four in $\mathrm{FN}$ ) in the autosome chromosomes in specimens trapped on Ilha Grande. The relation of $2 \mathrm{n}=61-65$ and the $\mathrm{FN}=$ 106-110 with the morphotype described as Trinomys dimidiatus remains uncertain, and variation observed in the present study (more frequent in continental samples) in the autosomal complement is usually described.

Specimens of Rhipidomys sp. differed from R. mastacalis by chromosomal complement and by cytochrome $b$ sequence analysis (mtDNA).

*2000. Pós-graduação em Biologia. Instituto de Biologia, Universidade do Estado do Rio de Janeiro, RJ, Brasil. Dissertação de Mestrado. Orienting professor: Dra. Lena Geise. 
Linkage map of Melipona quadrifasciata anthidioides (Hymenoptera: Apidae, Meliponinae) constructed with molecular markers

\section{Mara Garcia Tavares*}

Melipona quadrifasciata, popularly known as "mandaçaia" is a species of stingless bee of great scientific interest due to its importance as a pollinator agent. Similarly to most Hymenoptera, this species presents arrhenotokous parthenogenesis in which haploid males develop from unfertilised eggs and females from fertilised eggs. M. quadrifasciata apparently has a single-locus, multiple-allele sex determination system. However, linkage among the sex loci and other classical genetic markers is not available for this species. The present study is the first report of a genetic map for this species. The limited available genetic information about $M$. quadrifasciata was expanded and the characterisation of the system for sex determination in this species enhanced. Three types of polymorphisms were detected: band presence/absence, band intensity and fragment-length polymorphisms. The analyses revealed 22 linkage groups, ranging from 211.1 to $11.1 \mathrm{cM}$, with 38 unlinked makers. These 22 linkage groups included 89 RAPD markers and covered a genetic distance of approximately $1416 \mathrm{cM}$. In addition to the RAPD markers, the segregation pattern of the enzymatic marker $H b d h$ was also analysed to incorporate it into the linkage map. However, this marker was not linked to any of the RAPD loci analysed, and could not be added to the map. The posterior introduction of this locus to the of M. quadrifasciata linkage map would be interesting, especially because of the low frequency of enzymatic polymorphisms in Hymenoptera. Linkage between locus X and RAPD markers was not detected by several tests. These results indicated that the present map underestimated the total length of the $M$. quadrifasciata genome since the haploid chromosome number for this species is $\mathrm{n}=9$ and 22 linkage groups were detected. Another indicative of possible underestimation is the presence of large intervals (28 to $40 \mathrm{cM}$ ) between adjacent markers, present in some linkage groups. Further analyses, increasing the number of primers and drones, will be necessary to fill the gaps to saturation in the present map. Additionally, the introduction of 39 unlinked markers (38 RAPD and 1 enzymatic loci) to the map will probably increase its dimension. The saturation of this map with other markers will permit comparisons with maps already known for other species of Hymenoptera, and will also facilitate the characterisation of the system of sex determination of this species. Thus, the present map represents an initial step for future genetic analyses of the $M$. quadrifasciata genome.

*1999. Departamento de Biologia. Instituto de Biociencias, Letras e Ciências Exatas de São José do Rio Preto (IBILCE/ UNESP).São José do Rio Preto, SP, Brasil. Doctoral thesis. Orienting Professor: Dra. Maria Tercilia Vilela de Azeredo Oliveira.
Occupational genotoxicity evaluation in workers in the south of the state by the micronucleus test and comet assay

\section{Maria da Graça Martino Roth*}

Using two genotoxicity tests to analyze the samples, the occupational genotoxic risk of workers in small companies and informal workers in mechanical shops, painting, storage battery renovation (frequently working in the same place) was evaluated. Since these workers do not belong to important companies, they have no access to any kind of information on professional risks or their minimization, either from the government or their unions. In an attempt to warn about the risks of genotoxicity, one of those populations was evaluated.

The micronucleus test in exfoliated buccal cells and the comet assay test in peripheral blood were used to evaluate genotoxicity. These two techniques were chosen because they are not invasive, but are sensitive and accepted by researchers of international level.

The micronucleus test was applied to a sample of $60 \mathrm{oc}-$ cupationally exposed workers and 80 workers in several activities not considered of risk. The exposed workers were divided in to three sub-groups: mechanics, painters and storage battery renovators. The exposed workers showed a frequency of epithelial cells with micronucleus (CMN) significantly $(\mathrm{p}<0,001)$ increased $(8,22 \pm 4,34 \mathrm{CMN})$ in relation to the control $(2,12 \pm 1,62 \mathrm{CMN})$. The age, working time, smoking and alcoholic habits did not influence significantly the results.

The comet test was applied in a group of 10 painters and 10 storage battery renovators with its proper controls, jointly with the micronucleus test in buccal epithelium to compare the efficiency of the methods. In both tests the occupationally exposed showed highly significant $(p<0,001)$ results when compared to the controls. The average comet size in painters was $33,85 \pm 0,507 \mu \mathrm{m}$, in battery renovators it was $34,18 \pm 0,484 \mu \mathrm{m}$ and in the controls, it was $30,73 \pm$ $0,162 \mu \mathrm{m}$ and $30,54 \pm 0,136 \mu \mathrm{m}$, respectively. The damage index in painters was $12,8 \pm 6,67$; in battery renovators it was $13,6 \pm 6,18$, and in the controls, $1,8 \pm 1,61$ and $1,2 \pm 1,03$, respectively. The micronucleus frequency was $6,90 \pm 2,92$ CMN in painters, $6,60 \pm 3,27 \mathrm{CMN}$ in battery renovators and $2,20 \pm 1,75$ and $2,00 \pm 1,05 \mathrm{CMN}$ in the respective controls.

Both methods were consistent in detecting significant differences between the exposed groups and controls, and as well as great interindividual variability which results from different responses of each individual to genotoxic action, indicating that the evaluated workers constitute a risk group, for being exposed to genotoxic agents.

Its important to be pointed that the methodologies used were efficient and easily applied. The micronucleus and comet assay tests methodology used to evaluate the occupational genotoxicity, can also be used for environmental problems.

This, like other works, intend to be an alert to the organizations and groups that worry or that should worry 
about the occupational problems, when only big companies usually deserve attention. These populations of excluded, like those appraised in this work, make up a number several times superior to those of big companies and of unionized workers, that usually, even in equivalent activities, works in safer and salutary conditions.

"The prevention of cancer and other related mutation diseases, can be promoted, avoiding the exposition to recognized mutagenics/carcinogenics or reinforcing the need of using protection mechanisms" (De Flora, 1998).

*1999. Departamento de Zoologia e Genética. Instituto de Biologia, Universidade Federal de Pelotas, Rio Grande do Sul, Brasil. Doctoral thesis. Orienting Professor: Dra. Judith Viégas.

\section{Analysis of the integrity and number of copies of hobo and $P$ transposable elements in Brazil- ian Drosophila melanogaster populations}

\section{Mariangela Torreglosa Ruiz*}

Eight Brazilian strains of Drosophila melanogaster were studied for occurrence, copy number and integrity of hobo and $P$ transposable elements. PCR analysis indicated the presence of complete and deleted sequences of both elements in all the strains. The mean number of copies for hobo elements was $22.13 \pm 4.52$ and $13.75 \pm 3.15$ for $P$ elements. The hobo element copy number did not show association with the geographical origin of the strains; but the $P$ element copy number in strains from tropical regions was lower than that from temperate regions $(t=3.74 ; \mathrm{p}<0.05)$. Southern analysis was carried out to evaluate the hobo element integrity by digesting genomic DNA with Xho I endonuclease and probing it with a $963 \mathrm{bp}$ hobo sequence The blots showed the presence of a $2.6 \mathrm{~kb}$ fragment in all the strains, corresponding to the complete hobo element. A $1.0 \mathrm{~kb}$ fragment was also observed in all the strains, which probably corresponded to a repressor element. The analysis of $P$ element integrity was performed by digesting genomic DNA with Ava II and Dde I and probing it with a $2.9 \mathrm{~kb}$ and $986 \mathrm{bp}$ (Puv II fragment) sequences of $P$ element, respectively. Complete and defective elements were detected in all the strains, in variable quantities. The repressor $K P$ element was detected among the defective sequences. The high number of $K P$ elements and the phenotypic features of these strains regarding the P-M system suggest that $D$. melanogaster populations from the North of Brazil resemble the North American populations, while those from the South resemble the Eurasian ones. These findings might be explained by the occurrence of more than one introduction of individuals with $P$ elements into the Brazilian Drosophila melanogaster populations.

*2001. Departamento de Biologia, Instituto de Biociências, Letras e Ciências Exatas, UNESP, São José do Rio Preto, SP, Brasil, Master's thesis. Orienting Professor: Dra. Cláudia Márcia Aparecida Carareto.
Cytogenetic, cytochemical and ultrastructural analyses of spermiogenesis of the species of the Physalaemus and Pseudopaludicola falcipes with emphasis of the taxonomic characterization of the Physalaemus biligonigerus and $P$. fuscomaculatus (Amphibia, Anura)

Mauricio J. Lopes Vaz do Amaral

The Physalaemus genus, belonging to the Leptodactylidae family, shows extensive polymorphism and an abundance of cryptic species. At least four species are currently recognized in this genus. Some aspects of the cytogenetics and spermiogenesis of several species in this genus were investigated with particular emphasis on $P$. fuscomaculatus and $P$. biligonigerus. These two species are difficult to distinguish, mainly because of their considerable morphological similarities. A further problem is that the specific name fuscomaculatus has been applied to several biligonigerus populations. All the $P$. fuscomaculatus, $P$. biligonigerus and $P$. aff. biligonigerus specimens analyzed had $2 n=22$ chromosomes. All of the chromosomes had the same morphology, with the exception of pair 3 of $P$. fuscomaculatus, which was submetacentric, but metacentric in the other two species. The short arm of chromosome 3 contained a block of heterochromatin which was C-band positive and slightly longer in $P$. biligonigerus and $P$. aff. biligonigerus than in $P$. fuscomaculatus. The divergence in the morphology of chromosome 3 can be explained by the addition or deletion of heterochromatin. The three species also showed a large block of pericentromeric heterochromatin on pair 8, a small interstitial C-band on the long arm of pairs 5 and 7, as well as a single ribossomal cistron, on the long arm of chromosome 9, coincident with the secondary constriction. $P$. aff. biligonigerus was the only species to have a large block of pericentromeric heterochromatin on the short arm of chromosome 9 and another one on the telomeric band of the long arm. The nuclear basophilia during spermiogenesis in $P$. fuscomaculatus and P. biligonigerus (biligonigerus group), $P$. riograndensis, $P$. centralis, $P$. lisei, $P$. gracilis and $P$. cuvieri (cuvieri group) and $P$. petersi (pustulosus group) showed different responses with toluidine blue (TB) $\mathrm{pH} 4.0$ and alkaline fast-green (AFG) after the deamination. The spermatozoa of $P$. fuscomaculatus, $P$. biligonigerus, $P$. cuvieri and $P$. gracilis stained violet, whereas those of the other species showed different responses to TB. The spermatozoa of all species were positive to AFG, except in P. gracilis, even after deamination. These results show that the DNA in the spermatozoa of these species is differently complexed to proteins. This is the first description of such intrageneric variability in the Leptodactylidae. An ultrastructural analysis of the spermatozoa of $P$. fuscomaculatus, $P$. biligonigerus, $P$. gracilis and Pseudopaludicola falcipes, a genus considered to be a sister-group of Physalaemus, showed 
that the three species of Physalaemus had the same ultrastructural morphology, but differed from the spermatozoa from the Pseudopaludicola and other leptodactylids, in that they had no axial rod. The results obtained here were insufficient to prove that $P$. fuscomaculatus and $P$. biligonigerus are the same species, since the differences observed were very small and could reflect polymorphisms within populations. Although the Pseudopaludicola genus originated within the Physalaemus genus, the ultrastructure of $P$. falcipes spermatozoa differed from the latter group and was more similar to that of another leptodactylid, Odontophrynus cultripes. The use of a wider set of characters would help in elucidating the still confused phylogenetic relationships among leptodactylids.

*2000. Departamento de Biologia Celular. Instituto de Biologia, UNICAMP, Campinas, SP, Brasil. Doctoral thesis. Orienting Professor: Dra. Shirlei Maria Recco-Pimentel.

\section{Morphological, bioacustic and cytogenetic char- acterization of four species of Anurogryllus (Orthoptera, Gryllidae) from São Paulo state}

\section{Paula García-Novo*}

Morphological, bioacustic and cytogenetic studies were carried out in 174 specimens of the cricket genus Anurogryllus collected in six different localities in São Paulo State. The following morphological structures were analyzed: female and male genitalia, the pars stridens teeth, the general body color and the color pattern on several body regions in males. The kind of song that received most attention was the calling song because it enclosed species-specific information but courtship and agressivity songs as well courtship and mating behaviors were also studied. Meiotic and mitotic chromosomes were analyzed with standard and differential staining techniques such as C-banding, Ag-NOR and, in some cases, BrdU incorporation followed by FPG staining.

The majority of the morphological structures did not provide solid criteria to group the specimens, but only circumstantial evidence based in size and color differences that allowed a preliminary distribution of the specimens in four different groups.

The calling song analysis was decisive to identify Anurogryllus sp1 because the song emission in this species is discontinuous, which makes it different from that presented by all the remaining known species. The calling song structure also allowed the separation of two species from a single locality that were named Anurogryllus sp2 (univoltine) and Anurogryllus sp3 (bivoltine). Anurogryllus sp4 could not be distinguished from Anurogryllus sp2 because they both show similar calling songs.

The standard chromosome analysis showed that $\mathrm{Anu-}$ rogryllus sp3 has a characteristic karyotype, while the remaining species have differences that, without a preliminary grouping based on morphology and bioacustic criteria, could be interpreted as intraspecific variations. Regarding the differential staining techniques, the Ag-NOR did not provide useful information for group discrimination. The C-band, however, showed some differences that allowed the separation of Anurogryllus sp1 and Anurogryllus sp3 from Anurogryllus sp2 and Anurogryllus sp4.

Bearing in mind the problem of Anurogryllus sp4 whose body size similar to Anurogryllus sp3, variable body color and chromosomes similar to Anurogryllus sp2, a multivariate statistic test was carried out with morphological and song characteristics to quantify the differences, especially between Anurogryllus sp2 and Anurogryllus sp4. The results confirmed that it is possible to separate the Anurogryllus specimens into four different species. The characteristics of each one were compared with the remaining already described Anurogryllus species, confirming the existence of four new species in the genus.

*2000. Departamento de Biologia. Instituto de Biociências, UNESP, Rio Claro, SP, BRASIL. Master's thesis. Orienting Professor: Dr. Sanae Kasahara.

\section{Confined placental mosaicism in association with newborns small for gestational age}

\section{Síntia Iole Nogueira*}

Three groups of newborns were studied to investigate the presence of confined placental mosaicism associated with intrauterine growth retardation. The first group consisted of newborns with low birth weight for the gestational age without clinical reasons that could justify this event. The second group consisted of newborns small for gestational age, but presenting clinical reasons for the intrauterine growth retardation and the third group of newborns had appropriate weight in relation to the gestational age.

A cord blood sample and a placenta fragment were collected, immediately after the birth. The placenta cells were analyzed by Fluorescent In Situ Hybridization (FISH) and the cord blood cells were analyzed by the $\mathrm{G}$ banding cytogenetic method.

The probes utilized were for chromosomes 16 (heterochromatic region), 2 (centromeric region) and 7 (centromeric region) that are the chromosomes more frequently found in confined placenta mosaicism.

The cord blood results were normal and sex compatible. In relation to the placental samples, the first group presented the highest frequency of chromosome aneuplodies. This fact demonstrates a true relation between confined placental mosaicism and intrauterine growth retardation.

When we compared that the average of aneuploidies confined to stroma f first group was 36 per individual and that the average of aneuploidies confined to trophoblast was 24 per individual, we observed that the Type II ( 
aneuploidies confined to stroma) was more frequent and the difference between the averages was statistically significant.

Chromosome 16 was the most frequently involved in the stroma cells, followed by chromosomes 2 and 7, and this finding is in line with the literature. In trophoblast cells, chromosome 7 was the most frequently involved, followed by chromosomes 16 and 2 .

We consider that conclusions can be helpful for geneticists, pediatricians and obstetricians in understanding intrauterine growth retardation, since this phenomenon is related to increased morbidity and mortality rate in newborns. So, the assessment of pregnant women and their babies could be better and more efficient.

*2000. Disciplina de Genética. Departamento de Morfologia, Universidade Federal de São Paulo, Escola Paulista de Medicina, São Paulo, SP, Brasil. Master's thesis. Orienting Professor: Prof $^{a}$ Dr $^{a}$ Leila Montenegro Silveira Farah.

\section{Evaluation of segregating progenies, clonal families, apomictic $F_{1}$ hybrids and cultivars of guineagrass (Panicum maximum jacq.) as to aluminum stress in nutritive solutions}

\section{Antonio Carlos de Oliveira*}

Eighteen segregating progenies, eight clonal families derived from them, 15 apomictic $F_{1}$ hybrids and three cultivars of guineagrass were evaluated as to their reactions to the presence of aluminum $\left(\mathrm{Al}^{+3}\right)$ in nutritive solutions. Greenhouse trials were carried out in randomized complete block designs (split-plots), with three replications, at the Genetics Department-IAC, Campinas, SP, Brasil, from 1995 to 1997.

Fourteen characters were analyzed, as follows: plantlet height (PH); leaf blade length (LBL); initial (IRL), overall (ORL) and liquid root length (LRL); plantlet height percentual reduction (PHPR); overall (ORLPR) and liquid root lenght percentual reduction (LRLPR); fresh and dry weight of the above-soil fraction (FWASF; DWASF); fresh and dry weight of the root system (FWRS; DWRS) and respective dry/fresh weight relations (DWASF/FWASF; DWRS/FWRS). Nutritive solutions at two (zero and 12 ppm) and three (zero, 12 and $24 \mathrm{ppm}) \mathrm{Al}^{+3}$ concentrations were used, according to the situation, with $\mathrm{pH}$ adjusted to 4.0, and three time periods (15, 30 and 45 days) of the genotypes.

For the segregating progenies derived from $\mathrm{cv}$. "IAC-Centauro", the best time period for character evaluation was 45 days, based on the occurrence of the highest values for two genetic parameters (genetic variation and genotype determination coefficients) of the traits considered (PH and LRL). However, these criteria were not effective for those arisen from cv. "IAC-Tobiatã", the same time period (45 days) being arbitrarily chosen.

Other genetic parameters (heritability, in the narrow sense - $\mathrm{h}_{2} \mathrm{r} \%$, genotype determination coefficient - $\mathrm{b}$, absolute - agg and relative - $\mathrm{rgg} \%$ genetic gains) were also estimated. "IAC-Tobiatã" segregating progenies revealed higher values for the estimated genetic parameters, as compared to those derived from "IAC-Centauro" (PH: $\mathrm{h}^{2} \mathrm{r} \%=$ 78.01 and 52.98; $\mathrm{b}=0,77$ and 0.43 ; agg $=5.50$ and 1.81; $\mathrm{rgg} \%=17.05$ and 5.68, respectively / LRL: $\mathrm{h}^{2} \mathrm{r} \%=76.15$ and $58.60 ; \mathrm{b}=0.73$ and 0.48 ; $\mathrm{agg}=2.72$ and $1.27 ; \mathrm{rgg} \%=$ 13.84 and 6.45 , respectively).

Eight clonal families were formed through vegetative propagation of individual plants, selected for probable resistance/tolerance to the presence of $\mathrm{Al}^{+3}$ within the segregating progenies. Four of them confirmed the resistance/tolerance levels of the original genotypes (CF-5 - resistant; CF1, CF2 and CF4 - tolerant), while the remaining ones showed susceptibility to the stress.

Finally, 15 apomictic $F_{1}$ hybrids and three guineagrass cultivars were evaluated as to the behavior of the above mentioned forage traits under aluminum stress (zero, 12 and 24 ppm). For these genotypes, along with the clonal families, an $\mathrm{Al}^{+3}$ reaction classification system was proposed, based on principal component analysis (PCA), with the identification of four different groups: resistance, tolerance, sensibility and susceptibility. Apomictic hybrids H12, H13, H54, H79 and cv. IAC-Centenário were classified as resistant plant materials; H33 and cv. IAC-Tobiatã as tolerant ones; H38, H42, H55, H56, and H64 as sensible, and H10, H21, H22, H31, H140, and cv. IAC-Centauro as susceptible.

Considering each of the three $\mathrm{Al}^{+3}$ concentrations as a different environment, phenotype adaptability and stability were estimated, according to EBERHART \& RUSSEL's model. The genetic materials under testing were placed into five distinct groups: a) high adaptability and response predictability: H12, H13, H33, H79, and cv. IAC-Centenário; b) average adaptability and high response predictability: H21, H22, H42, H54, H56, H64, and cv. IAC-Tobiatã; c) average adaptability and low response predictability: H31 and $\mathrm{H} 38$; d) low adaptability and high response predictability: H55 and cv. IAC-Centauro; and e) low adaptability and response predictability: $\mathrm{H} 10$ and $\mathrm{H} 140$.

The association between PCA and stability/response predictability showed good precision for genotype differentiation as to the aluminum reaction, strongly suggesting its use in future breeding programs.

Research supported by FAPESP.

*1997. Departamento de Genética e Evolução. Instituto de Biologia, Universidade Estadual de Campinas, Campinas, SP, Brasil. Master's thesis. Orienting Professor: Dr. José Alfredo Usberti Filho. 
Analysis of polymorphic nucleolus organizer regions in the rainbow trout (Oncorhynchus mykiss): inheritance mechanism and effects on development

\section{Fábio Porto-Foresti*}

Cytogenetic analyses were performed in rainbow trout samples from ten captive stocks cultivated by different farmers over highland areas in the States of São Paulo, Minas Gerais and Rio de Janeiro, and also from a wild population collected in the Gavião River (SP), in an attempt to characterize the distribution of ribosomal genes . Results based on the Ag-NOR technique for the identification of chromosome nucleolar organizing regions (NORs) revealed differences among the populations. NORs were always found in a subterminal position on the short arm of a submetacentric chromosome pair in samples from the Isle of Man and Denmark, imported by the Brazilian Association of Salmon Aquaculture and maintained by the Experimental Center of Salmon Aquaculture at Campos do Jordão (SP), as well as in the samples from Mount Shasta and Kamloops, held by the N.R. Center for Salmon Aquaculture at Sapucaí Mirim (MG) and in samples from the USA, Denmark and from a local stock cultivated at the Hotel Fazenda São João in Nova Friburgo (RJ). In the samples from Teresópolis (RJ), maintained at Aquacultivo Montenegro, AQUA Ltda., at Serra da Bocaina (SP), and from Japan, maintained by the Experimental Center of Salmon Aquaculture at Campos do Jordão, NORs were frequently located in that same position, but in some specimens, while one mark was observed at the mentioned site, another spot was found in a subterminal position on the long arm of an equally submetacentric chromosome. These results suggest the occurrence of hybridization involving individuals of the former stocks of Teresópolis, AQUA and Japan and of the Experimental Center of Salmon Aquaculture at Campos do Jordão. Specimens sampled from an introduced wild population from the Gavião River presented NORs located in a similar position to that observed in fishes from Campos do Jordão, suggesting a common origin for those stocks, probably California, from where the species was first imported in 1962. By using the fluorescent in situ hybridization technique (FISH), the chromosomal location of ribosomic DNA was assessed in samples examined with a $18 \mathrm{~S}$ rDNA probe, showing the same marks as obtained by using the Ag-NOR staining method. Such marks were observed on two chromosome pairs in the four samples analyzed with a 5S rDNA probe. Their location was similar in all samples analyzed, i.e., pericentromeric in a pair of subtelocentric chromosomes, and interstitial on the long arm of a pair of submetacentric chromosomes. In the submetacentric pair, the genes for $18 \mathrm{~S}$ and 5S rDNA occupy adjacent positions, and the alteration to an interstitial position on the long arm, as identified in the stocks from Campos do Jordão and Gavião River, in contrast to those found in the other described pools, may be the result of a pericentric inversion or translocation involving the NOR-bearing chromosome segment. These chromosome alterations appear to have taken place in the original stock, having possibly already been present in the introduced specimens, which gave rise to the populations currently found in those localities. The observed polymorphism is considered to be a genomic marker of wide potential usage, and could constitute a useful tool in the genetic management and culture of the studied species. In order to identify the chromosomes with NORs and their alterations, crossbreeding was induced between specimens from Campos do Jordão bearing a NOR on the long arm of a submetacentric chromosome pair, and specimens from the Mount Shasta stock, in which the NOR is located in a subterminal position on the short arm of a submetacentric chromosome pair. Cytogenetic analysis performed in the offspring using the Ag-NOR staining technique allowed to identify silver precipitate spots on two submetacentric chromosomes, located respectively on the short and on the long arms. This result provides real evidence of the hybridization process. However, since the involved chromosomes are of similar size and morphology, better chromosome identification in different stocks could be obtained by using longitudinal banding techniques or crossbreeding between F1 individuals. This information would be relevant to the management of the rainbow trout, since there is a possibility of producing non-viable progeny due to lacking nucleolar chromosomes, if parental NORs are located on different chromosomes. Different NOR-related phenotypes were examined to test for differential growth. A comparison was made between individuals from the Experimental Center of Salmon Aquaculture at Campos do Jordão, identified as N1N1 and N1N2 according to a new inversion detected in this chromosome segment. Previous investigation indicated the absence of the N2N2 phenotype (homozygotic for the chromosome inversion), a non-viable (NOR)-lacking strain. Growth comparisons of weight and length between 24 homozygotic N1N1 individuals (simple NORs) and 36 heterozygotic N1N2 specimens (with chromosome inversion), reared under the same conditions and measured for biometric variables every 3 months, did not show significant differences, neither between the average growth values, nor between the weight $x$ length rate for any sampled period. The results obtained may indicate the neutrality of the $\mathrm{N} 2$ condition when in heterozygosis, since no effects on viability or growth were detected in individuals carrying such nucleolar organizer characteristics.

*2001. Laboratório de Biologia e Genética de Peixes, Departamento de Morfologia, IB, UNESP, Botucatu, SP, Brasil. Doctoral thesis. Orienting Professor: Claudio Oliveira. 


\section{Allele frequency of loci DYS390, DYS391 and DYS393 in Brazilian subjects and its use for hu- man identification}

\section{Rogério Nogueira de Oliveira*}

Human identification can be accomplished by several technical procedures, including the comparative analysis of dental documents. Nowadays, more effective resources for human identification were introduced by molecular biology. However, these methods demand the previous definition of parameters for the collection of biological material, and the verification of the allele frequency of the population in which they will be applied. Aiming at subsidizing these methods, we observed the allele frequency of three STR loci on the Y chromosome (DYS390, DYS391 and DYS393) in a group of Brazilian white subjects. We also standardized protocols for the collection and storage of different biological materials, besides defining routines for DNA extraction and amplification . Our results showed alleles $21,22,23,24,25$, and 26 at the DYS390 locus, allele 24 being the most frequent one with $46 \%$. At the STR DYS391 locus, (presented) we found alleles 8, 9, 10, 11, 12 , and 13 , and the most frequent one was allele 11, with $37 \%$. The STR DYS393 locus presented alleles 11, 12, 13, 14 , and 15 , and allele 13 was the most frequent one, with $45 \%$. The analysis of these data, as compared to information regarding other populations, stresses the singularity of the allele profile of the studied population. Therefore, before introducing recent molecular biology methods for human identification, we should carefully verify the allele patterns of the population, because the use of allele standards of other populations may produce imprecision in the process of human identification.

*2001. Faculdade de Odontologia de Piracicaba, UNICAMP, Sorocaba, SP, Brasil. Doctor's Thesis. Orienting Professor: Dr. Heloísa A. Lima Castro.

\section{Contributions to the systematics of Akodon (Rodentia: Cricetidae: Sigmodontinae) from eastern Brazil: an anatomic, cytogenetic and geographic approach}

\section{Alexandre Uarth Christoff*}

Morphological comparisons were carried out from a sample of 311 specimens of the Akodon genus, all of them karyotyped, from eastern Brazil, from Rio Grande do Sul state to Paraíba state. Five species species have been recognized as a result of these combined analyses: Akodon cursor $(2 \mathrm{n}=14,15,16)$, Akodon montensis $(2 \mathrm{n}=24,25,26)$, Akodon lindberghi $(2 \mathrm{n}=42)$, Akodon serrensis $(2 \mathrm{n}=46)$, and Akodon sp. n. $(2 \mathrm{n}=44)$. The diploid number associated with the karyotype morphology constitutes a characteristic diagnostic of these species.
In this paper, species recognition was made through the association of cytogenetic information with anatomic comparisons, which included external, skull and teeth morphology, phallus anatomy and statistical analysis of 20 cranial measurements.

Akodon cursor $(2 \mathrm{n}=14,15,16)$ is a species featuring a complex rearrangement in pair 1 . This is composed of two pairs of submetacentric chromosomes with different sizes in the karyotype with $2 \mathrm{n}=16$; in animals with $2 \mathrm{n}=14$, it presents a large metacentric homozygous pair; the heterozygotes with $2 \mathrm{n}=15$ bear a large metacentric chromosome and two submetacentric ones, all of them registered only in the state of Paraná, São Paulo and Rio de Janeiro. Additionally, high chromosomal polymorphism occurs due to pericentric inversions involving pairs 2 and 3 and, with low frequency, pair 5. Polymorphism is so high that in one sample with 16 specimens, ten diverse karyotypical constitutions were reported in the region of Iguape, São Paulo. The karyotype with $2 \mathrm{n}=16$ is fixed ina sample from Pernambuco stae, and it occurs with low frequency in Guaraqueçaba Bay, eastern Paraná state, and it has been found recently in other samples from Cananéia (Ariri) and Iguape, in São Paulo state, thus increasing this cytotype record for the southeastern population. A. cursor is distributed from the southeast to the northeast of Brazil occurring mainly in the Brazilian Atlantic Rain Forest.

Akodon montensis $(2 \mathrm{n}=24,25,26)$ presents three changes in the karyotypical constitution: a) occurrence of an accessory chromosome, causing variation both in the diploid number and in the number of autosomal arms (NA); b) occurrence of $\mathrm{X} 0$ females, monosomic for chromosome $\mathrm{X}$; and c) constitution incompatible with the phenotypical sex, that is, $\mathrm{XY}$ females. This species is widespread in South America, occupying areas in the Chaco, northern Argentina, and in the Cerrado, inland São Paulo state, as well as in the Semideciduous Seasonal Forest, in the Mixed Moist Forest, and in the Atlantic Rain Forest in southeastern and southern Brazil.

Hybrids $(2 \mathrm{n}=19,20)$ between $A$. cursor and $A$. montensis have been reported in Iguape, São Paulo, in the ecotones between the slope forest and the coastal plain forests. These ecotones constitute areas of contact between these species. The anatomy of hybrid specimens between A. cursor and A. montensis species does not differ from the anatomy of parental adult species, and it presents an intermediary position when scores are projected on a bi-dimensional graph, where the axles represent the principal components 1 and 2 .

In $A$. cursor and $A$. montensis, the interorbital breadth is slightly wider than reported for Akodon sp. $(2 \mathrm{n}=44)$. These species present neither an ectolophid nor a developed ectostylid, but bear their first molar with well-defined anteromedian flexus/flexid.

In A. cursor and A. montensis, the phallus presents a three-digit distal baculum with wide lateral digits when 
laterally viewed, bearing a more tapering central element. The distal baculum anatomy is different from the other Akodon species studied.

Results of multivariate statistical analysis indicate that the changes in the cranial shape of the A. cursor and $A$. montensis rodents is allometric. Discriminant analysis provided a highly discriminatory function, enabling the correct classification of $96.6 \%$ of the cases.

The names attributed to the two karyotypes and morphotypes have been defined by Rieger et al. [Bioch. Genet. 33(9/10):283-295] on basis of their respective type localities. The type locality of Akodon cursor (Winge, 1988) [E. Museo Lundii, 1888. 1(3):1-178.] is Lagoa Santa, Rio das Velhas, Minas Gerais, Brazil, and the type locality of A. montensis Thomas (1913) [Ann. Mag. Nat. Hist., 1913. 8(18):404-409.] is Zacupay, Paraguay. These species can be recognized as good examples of cryptic species, since they present high morphological similarity in cranial-dental anatomy, phallic anatomy, color pattern of pelage and in cranial dimensions, being differentiated only by their karyotypes.

Akodon serrensis Thomas (1902) [Ann. Mag. Nat. Hist., 1902. 7(9):59-64.] presents diploid number with 46 chromosomes, a robust molar row with the first upper and lower molars proportionally large, and a wide interorbital breadth. The pelage features a dark brown color pattern, matching that originally described by Thomas (1902). Another important observed feature was that the anteromedian flexus and flexid were absent in the first molars. The distal baculum bears reduced and short lateral digits. The type locality of Akodon serrensis is Roça Nova, in the town of Piraquara, Paraná, Brazil; ca 1000 m of altitude. This species is reported in the Mixed Moist Forest, near the city of Curitiba, Paraná state, and in the Brazilian Atlantic Rain Forest, states of São Paulo, Rio de Janeiro and Minas Gerais.

Akodon lindberghi Hershkovitz (1990) [Fieldiana Zool. (New Serie) 1990. 57:1-35.] presents a karyotype with $2 \mathrm{n}=42$ and is easily identified by its anatomic cranial-dental pattern and dimensions compatible with those originally described by Hershkovitz (1990). This species bears a typically small skull with an incisive condyle length shorter than $23 \mathrm{~mm}$, an upper molar row smaller than 4.2 $\mathrm{mm}$ and a phallus with short and robust baculum, as compared to other species. The type locality of $A$. lindberghi is Matosa, Parque Nacional de Brasília, DF, Brazil; ca 1100 $\mathrm{m}$ of altitude. A. lindberghi is known from only two localities: Brasília, Federal District, and Simão Pereira, Minas Gerais. The first locality is covered by Cerrado vegetation, and the second by Atlantic Rain Forest.

Akodon sp., a new species for the genus, presents a karyotype with $2 \mathrm{n}=44$ and a narrow interorbital breadth. The ratio between the interorbital breadth and the sum of the interorbital breadth plus the orbital fossa length, plus the upper molar row length is lower than 0.27 , which makes it different from all other species of Akodon studied here. Interorbital breadth corresponds to at most $23 \%$ of the basilar length. The most remarkable features for this species are: narrow interorbital breadth, the presence of ectolophid, a well-developed anteromedian flexus/flexid, and a reduced tympanic tegmen. Phallus analysis shows a distal baculum with the central digit and the lateral ones approximately equal in size, the lateral elements are not wide and bear a more tapering tip. Akodon sp. occurs in northeastern Argentina, eastern Paraná near Curitiba, and also in Rio Grande do Sul state. It occupies vegetal formations such as the Semideciduous Seasonal Forest, the Mixed Moist Forest and the Pioneer Vegetation of coastal sand, as in southern Brazil.

Akodon sp. $(2 \mathrm{n}=44)$ can be differentiated from $A$. sanctipaulensis Hershkovitz (1990) [Fieldiana Zool. (New Serie) 1990. 57:1-35.], a species described for state of São Paulo, with unknown karyotype, by a number of morphological characteristics: in the former, the skull is proportionally larger, and it has a lighter external color.

Discriminant analysis was applied to the sample of the five species of Akodon and generated a highly powerful discriminatory function, allowing the correct classification of $98.5 \%$ of the cases. Major variables integrating this function were: rostrum length; interorbital breadth; molar row length; fossa length; and braincase breadth.

*1997. Departamento de Biologia, Instituto de Biociências, Universidade de São Paulo, São Paulo, SP, Brasil. Doctoral thesis. Orienting Professor: Dr $r^{a}$ Yatiyo Yonenaga-Yassuda.

\section{Caryologic diversity of small-sized rodents from the State of Tocantins, Brazil}

\section{José Fernando de Sousa Lima*}

Small rodents were collected at different sites in the State of Tocantins, ascribed to three types of regions, according to the predominant vegetation: North, characterized by the Amazon (Rain) Forest, Mid-South and East characterized by the "Cerrado", and Mid-Araguaia consisting of the Bananal Island complex.

The chromosome preparations were submitted to conventional staining, as well as to G, C and NOR banding techniques. Chromosome differentiation was produced in the chromosomes of some individuals by cell treatment with ethidium bromide. A total of 102 specimens were karyotyped, belonging to 9 genera and 12 species: Bolomys lasiurus $(2 \mathrm{n}=34$ and $\mathrm{NA}=34)$, Calomys tener $(2 \mathrm{n}=66$ and $\mathrm{NA}=66)$, Calomys sp.n. $(2 \mathrm{n}=46$ and NA $=66)$, Nectomys rattus $(2 \mathrm{n}=52,53$ and $\mathrm{NA}=52,54)$, Oligoryzomys flavescens $(2 \mathrm{n}=64$ and NA $=66)$, Oligoryzomys sp.n. $(2 \mathrm{n}=$ 70 and NA = 76), Oryzomys megacephalus (Karyotype A with $2 \mathrm{n}=54$ and $\mathrm{NA}=62$; Karyotype $\mathrm{B}$ with $2 \mathrm{n}=52 / 53$ and NA $=58 / 60)$, Oryzomys gr. subflavus $(2 \mathrm{n}=46$ and NA $=56)$, and Rhipidomys macrurus $(2 \mathrm{n}=44$ and NA $=48)$, 
belonging to the family Cricetidae; Proechimys roberti $(2 \mathrm{n}$ $=30$ and NA $=54)$ and Thrichomys apereoides $(2 \mathrm{n}=30$ and $\mathrm{NA}=54$ ), belonging to the family Echimyidae, and Rattus rattus $(2 \mathrm{n}=38$ and $\mathrm{NA}=58)$, belonging to the family Muridae. No chromosome preparations were obtained from Oecomys gr. concolor. Most of these species have been reported to occur in the Northern and Mid-Western regions of Brazil, and their karyology is already known. The karyotypes found were usually similar or identical to those reported in the literature, with rare cases of chromosome polymorphisms. Some specimens in the sample, i.e. Calomys sp.n. and Oligoryzomys sp.n., presented previously unreported karyotypes, probably corresponding to new species within their respective genera. A single specimen of Oryzomys megacephalus showed a Karyotype B different from that of the majority of this species, which had a higher chromosome number. Mosaicism is probably due to the occurrence of a supernumerary chromosome.

*2000. Departamento de Biologia, Instituto de Biociências de Rio Claro, Universidade Estadual Paulista - UNESP, Rio Claro, SP, Brasil. Doctoral thesis. Orienting Professor: Dr. Sanae Kasahara.

\section{Comparisons of molecular markers and diallel crosses to assign maize lines to heterotic groups}

\section{Rogério de Melo Costa Pinto*}

The objective of this research was to compare the use of specific combining ability (SCA) estimates and RFLP molecular markers to allocate maize lines to heterotic groups. Eight $\mathrm{S}_{3}$ lines derived from population BR-105 and 10 derived from population BR-106 were crossed at intraand interpopulation levels following a diallel system. Eighty interpopulation single-crosses, and 28 and 45 intrapopulation single-crosses were obtained and evaluated in lattice designs across three environments. Data were recorded on grain yield (GY), plant height $(\mathrm{PH})$, ear height
$(\mathrm{EH})$, ear placement $(\mathrm{EP}=\mathrm{EH} / \mathrm{PH})$, and prolificacy (PROL).

General combining ability (GCA) and specific combing ability (SCA) estimates were computed according to Griffing's (1956) method 4, model I, for all traits. The RFLP molecular markers were analyzed using 88 DNA clones and 4 restriction enzymes, from which 1,429 polymorphic bands were scored. From these data the genetic distance (GD) between all pairs of lines were computed. Estimates of SCA and GD were used for principal coordinate analyses (PCO) and for cluster analyses using the UPGMA clustering algorithm to assign the lines to heterotic groups.

The lines were allocated to 4 heterotic groups from the estimates of SCA for the GY trait, in which the lines from each population were subdivided into two heterotic groups. From the RFLP data the lines were also allocated to four heterotic groups, and, also, the lines from each population were subdivided in two heterotic groups. The heterotic groups obtained from the CEC and RFLP analyses were quite similar, indicating that the use of molecular markers to assign lines to heterotic groups can be efficient. For the other traits, the use of the CEC estimates to assign lines to heterotic groups was not efficient.

The results showed that RFLP molecular markers were as efficient as analyses of the CEC estimates for the GY trait in allocating maize lines to heterotic groups. Thus, as grain yield is the main trait for breeding purposes, RFLP markers can be efficiently used to assign maize lines to heterotic groups, avoiding the need to obtain the crosses and their evaluation in replicated experiments and the statistical analyses of the experiments. Thus the time usually needed to allocate maize lines to correct heterotic groups can be considerably reduced by replacing the diallel analysis procedure by the RFLP maker analysis.

*2000. Departamento de Genética, Escola Superior de Agricultura "Luiz de Queiroz", ESALQ, Piracicaba, SP, Brazil. Orienting Professor: Dr. Cláudio Lopes de Souza Júnior. Co-Orienting Professor: Dra. Anete Pereira de Souza. 